\title{
Voltage Dependent N Type Calcium Channel in Mouse Egg Fertilization
}

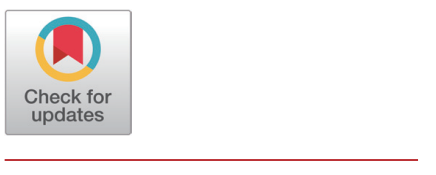

Received: November 26, 2020

Revised: December 2, 2020

Accepted: December 10, 2020

${ }^{+}$Corresponding author

Sook Young Yoon

Fertility Center of CHA Gangnam Medical

Center, Seoul 06125, Korea

Tel: +82-2-3468-2841

Fax: +82-2-3468-3466

E-mail:syyoon11@cha.ac.kr

Copyright $\odot 2020$ The Korean Society of Developmental Biology.

This is an Open Access article distributed under the terms of the Creative Commons Attribution Non-Commercial License (http://creativecommons.org/licenses/ by-nc/4.0/) which permits unrestricted non-commercial use, distribution, and reproduction in any medium, provided the original work is properly cited.

ORCID

Jin Hee Eum

https://orcid.org/0000-0002-7875-1870 Miseon Park

https://orcid.org/0000-0002-1821-8230 Jung Ah Yoon

https://orcid.org/0000-0003-4789-3806

Sook Young Yoon

https://orcid.org/0000-0002-4656-2899

Conflict of interests

The authors declare no potential conflict of interest.

Acknowledgements

This research was supported by a grant from National Research Foundation of Korea (NRF-2017 R1D1A1B03028155 and NRF-2018R1D1A1B07043250).

Authors' contributions

Conceptualization: Yoon SY, Eum JH.

Data curation: Yoon SY.

Investigation: Eum JH, Park MS, Yoon JA.

Writing - original draft: Yoon SY.

Writing - review \& editing: Yoon SY, Eum JH.

\section{Ethics approval}

All the animals received humane care in accordance with the guides for

animal experiments of the Association

for Assessment and Accreditation of

\author{
Jin Hee Eum, Miseon Park, Jung Ah Yoon, and 'Sook Young Yoon \\ Fertility Center of CHA Gangnam Medical Center, Seoul 06125, Korea
}

\section{Abstract}

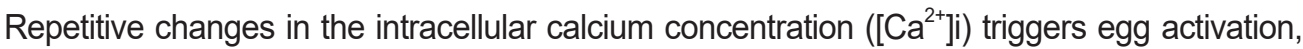
including cortical granule exocytosis, resumption of second meiosis, block to polyspermy, and initiating embryonic development. $\left[\mathrm{Ca}^{2+}\right]$ i oscillations that continue for several hours, are required for the early events of egg activation and possibly connected to further development to the blastocyst stage. The sources of $\mathrm{Ca}^{2+}$ ion elevation during $\left[\mathrm{Ca}^{2+}\right]$ i oscillations are $\mathrm{Ca}^{2+}$ release from endoplasmic reticulum through inositol 1,4,5 tri-phosphate receptor and $\mathrm{Ca}^{2+}$ ion influx through $\mathrm{Ca}^{2+}$ channel on the plasma membrane. $\mathrm{Ca}^{2+}$ channels have been characterized into voltage-dependent $\mathrm{Ca}^{2+}$ channels (VDCCs), ligand-gated $\mathrm{Ca}^{2+}$ channel, and leak-channel. VDCCs expressed on muscle cell or neuron is specified into L, T, N, P, Q, and R type VDCs by their activation threshold or their sensitivity to peptide toxins isolated from cone snails and spiders. The present study was aimed to investigate the localization pattern of $\mathrm{N}$ and $\mathrm{P} / \mathrm{Q}$ type voltage-dependent calcium channels in mouse eggs and the role in fertilization. $\left[\mathrm{Ca}^{2+}\right]$ i oscillation was observed in a $\mathrm{Ca}^{2+}$ contained medium with sperm factor or adenophostin $\mathrm{A}$ injection but disappeared in $\mathrm{Ca}^{2+}$ free medium. $\mathrm{Ca}^{2+}$ influx was decreased by Lat A. N-VDCC specific inhibitor, $\omega$-Conotoxin CVIIA induced abnormal $\left[\mathrm{Ca}^{2+}\right]$ i oscillation profiles in $\mathrm{SrCl}_{2}$ treatment. $\mathrm{N}$ or $\mathrm{P} / \mathrm{Q}$ type VDC were distributed on the plasma membrane in cortical cluster form, not in the cytoplasm. $\mathrm{Ca}^{2+}$ influx is essential for $\left[\mathrm{Ca}^{2+}\right]$ i oscillation during mammalian fertilization. This $\mathrm{Ca}^{2+}$ influx might be controlled through the $\mathrm{N}$ or $\mathrm{P} / \mathrm{Q}$ type VDCCs. Abnormal VDCCs expression of eggs could be tested in fertilization failure or low fertilization eggs in subfertility women.

Keywords: $\left[\mathrm{Ca}^{2+}\right]$ i oscillation, Fertilization, Voltage dependent calcium channel, Mouse eggs

\section{INTRODUCTION}

Calcium is a highly multifaceted intracellular messenger that controls a wide range of cellular functions by regulating the activity of numerous target proteins. Calcium functions by binding directly to a target protein, detecting changes in calcium concentration, and then activating various downstream reactions (Berridge, 2014). During mammalian fertilization, phospholipase C zeta (PLCZ), a factor from sperm, induces repetitive changes in the intracellular calcium concentration $\left[\mathrm{Ca}^{2+}\right]$ i, termed $\left[\mathrm{Ca}^{2+}\right]$ i oscillations. These $\left[\mathrm{Ca}^{2+}\right]$ i oscillations are responsible for the initiation of fertilization event including, cortical granule exocytosis to block to polyspermy, resumption of meiosis, recruitment of maternal mRNAs and activation of embryonic genome, and further embryonic development (Ajduk et al., 2008). Once PLCZ were released into egg, PLCZ triggers activation of phosphoinositide 
Laboratory Animal Care at CHA University (Approval No. IACUC170141, IACUC200157).
(PI) pathway that produces IP3 and 1, 2-diacylglycerol (DAG) by hydrolysis of PIP2. Increase intracellular inositol 1,4,5, tri phosphate (IP3) concentration is in charge for mediating $\mathrm{Ca}^{2+}$ release from endoplasmic reticulum (ER) via IP3 receptor (IP3R) (Miyazaki et al., 1993; Malcuit et al., 2006; Yoon \& Kang, 2011$)$. The pattern of $\left[\mathrm{Ca}^{2+}\right]$ i oscillations in fertilized mouse eggs affects blastocyst formation and developmental competence (Ozil et al., 2006). The each of cellular event of egg activation or fertilization is controlled by a different number of $\left[\mathrm{Ca}^{2+}\right]$ i oscillations Experiments altering extracellular $\left[\mathrm{Ca}^{2+}\right]$ concentration in the middle of $\mathrm{Ca}^{2+}$ oscillations affected both the refilling rate and the rate of $\mathrm{Ca}^{2+}$ influx, which is in determining the intervals of $\mathrm{Ca}^{2+}$ transients. (Takahashi et al., 2013). The sources of $\left[\mathrm{Ca}^{2+}\right]$ i elevation during $\left[\mathrm{Ca}^{2+}\right]$ i oscillations are $\mathrm{Ca}^{2+}$ release from ER through IP3R and $\mathrm{Ca}^{2+}$ ion influx through $\mathrm{Ca}^{2+}$ channel on the plasma membrane. $\mathrm{Ca}^{2+}$ channels on the plasma membrane have been investigated in hormone sensitive cell, neurons, and skeletal and heart muscle cells and characterized into voltage-dependent $\mathrm{Ca}^{2+}$ channel (VDCCs), ligand-gated [ $\left.\mathrm{Ca}^{2+}\right] \mathrm{i}$ channel, and leak-channel. VDCCs expressed on muscle cell or neuron is specified into L, T, N, P, Q and R type VDCCs by threshold or their sensitivity to peptide toxins isolated from cone snails and spiders (Bourinet \& Zamponi, 2017). It has been shown that plasma membrane potentials of mammalian oocyte are changed according to their maturational stage from germinal vesicle stage to meiosis II stage that could be fertilized by sperm (Lee et al., 2004). Also, addition of VDCCs blockers inhibits mammalian oocyte maturation or embryo development (Petr et al., 1997; Hotsuliak et al., 2002). Summarizing these reports, the $\mathrm{Ca}^{2+}$ required for mouse egg maturation appears to have been separated by $\mathrm{Ca}^{2+}$ influx, but the $\mathrm{Ca}^{2+}$ origin of $\mathrm{Ca}^{2+}$ oscillations that appear during fertilization have not been reported.

The present study was aimed to investigate that the effect of extracellular $\mathrm{Ca}^{2+}$ on $\mathrm{Ca}^{2+}$ oscillation and $\mathrm{Ca}^{2+}$ influx through VDCCs during fertilization. Also, we investigated the localization of $\mathrm{N}$ and P/Q type voltage dependent calcium channel in mouse eggs and the role in fertilization and further embryonic development by using $\mathrm{N}$ type VDCCs specific inhibitor.

\section{MATERIALS AND METHODS}

\section{Animals}

Five to six weeks old ICR or C57BL/DBA F1 hybrid female mouse were purchased from Samtako (Seoul, Korea). Female mice were superovulated by 5 IU pregnant mare serum gonadotropin (PMSG; Lee Biosolution, Maryland Heights, MO, USA), followed by injection with $5 \mathrm{IU}$ human chorionic gonadotropin after $48 \mathrm{~h}$ (hCG, Sigma-Aldrich, St. Louis, MO, USA). Cumulus enclosed mature eggs were collected from oviduct at $14 \mathrm{~h}$ post hCG. Cumulus cells were removed with $0.1 \%$ hyaluronidase (Sigma-Aldrich) in HEPES-buffered Tyrode's lactate solution (TL-Hepes) medium (Parrish et al., 1988). All experiments described in this study were approved by the Institutional Animal Care and Use Committee (IACUC) of CHA University and performed in accordance with the guidelines presented by IACUC (Approval No. IACUC170141, IACUC200157).

\section{Measurement of intracelluar calcium concentration}

$\left[\mathrm{Ca}^{2+}\right]$ i changes were measured by loading eggs with $1 \mu \mathrm{M}$ Fluo- $4 \mathrm{AM}$ or fura-2-acetoxymethyl ester (Molecular Probes, Eugene, OR, USA), a $\left[\mathrm{Ca}^{2+}\right]$ i sensitive indicator dye, supplemented with 0.02\% pluronic acid (Molecular Probes) in TL-HEPES, and monitored under an Axiovert $200 \mathrm{M}$ microscope fitted with a $\times 10$ objective and CCD camera controlled with AxioVision software 4.8.1 (Carl Zeiss, Jena, Germany). $\left[\mathrm{Ca}^{2+}\right]$ i was monitored by measuring fluorescence from individual 
eggs loaded on a temperature-controlled chamber dish (SEC, Seoul, Korea) coated with CellTak ${ }^{\circledR}$ (BD Biosciences, San Jose, CA, USA). Microinjection of porcine sperm factor (pSF: prepared as in Kurokawa et al., 2005) or $10 \mu \mathrm{M}$ adenophostin A (Ad A, Cayman Chemical, Ann Arbor, MI, USA) was performed using a Nikon (Narishige, Japan) manipulator with a picoinjector (Femtojet, Effendorf, Hamburg, Germany) via pneumatic pressure (Kim et al., 2011). Thapsigargin (TG, 10 $\mu \mathrm{M}$, EMD Biochemicals, Gibbstown, NJ, USA) was employed for assessment of the releasable $\left[\mathrm{Ca}^{2+}\right] \mathrm{i}$ content in eggs, and strontium chloride $(10 \mathrm{mM} \mathrm{SrCl} 2)$ was added in $\left[\mathrm{Ca}^{2+}\right] \mathrm{i}$ free TLHEPES medium. 2.5 $\mu \mathrm{M}$ Latrunculin A (Lat A, Calbiochem, San Diego, CA) were applied for actin polymerization inhibitor that modifies the organization of the egg cortex and inhibit $\left[\mathrm{Ca}^{2+}\right] \mathrm{i}$ oscillation (Lee et al., 2016).

\section{Immunostaining for $\mathrm{N}$-type or $\mathrm{P} / \mathrm{Q}$ type VDCCs distribution}

Immunostaining of eggs was carried out as described in a previous report (Kim et al., 2011). In briefly, zona pellucida were removed with acid-Tyrode's solution ( $\mathrm{pH}$ 2.5, Sigma-Aldrich), and fixed in $4 \%$ paraformaldehyde and $0.1 \%$ Tritone X-100 for $30 \mathrm{~min}$ at $4{ }^{\circ} \mathrm{C}$. Eggs were blocked in protein block (Dako, Glostrup, Denmark) for $2 \mathrm{~h}$ at $4^{\circ} \mathrm{C}$, followed by incubation with an antiCACNA1B ( $\left.\mathrm{Ca}_{\mathrm{v}} 2.2\right)$ antibody for N-type VDCC or anti-CACNA1B $\left(\mathrm{Ca}_{\mathrm{v}} 2.1\right)$ antibody for P/ Q type VDCC (1:100) for overnight. Eggs were stained with Alexa Fluor 555 goat anti-rabbit IgG (1:200, Molecular Probes), FITC-phalloidin (Molecular Probes), and DAPI (Molecular Probes), and mounted in VECTASHELD mounting medium (Vector Laboratories, Burlingame, CA, USA). Mounted eggs were observed with using a laser scanning confocal microscope with the Z-stack (LSM 880, Carl Zeiss, Germany). The primary antibody were omitted for negative control. For immunostaining of blastocysts, blastocysts were treated with acid-Tyrode's solution to remove zona pellucida, and fixed in $4 \%$ paraformaldehyde and $0.1 \%$ Tritone $\mathrm{X}-100$ for $30 \mathrm{~min}$ at $4{ }^{\circ} \mathrm{C}$. Immunofluorescence analysis was performed for inner cell mass (ICM) with anti- oct- $3 / 4$ antibody and trophectoderm (TE) with actin-phalloidin and total cell number with DAPI.

\section{In vitro fertilization and differential staining of blastocyst}

Sperm was collected from epididymis of 12-week-old male mice in HTF supplemented with 5\% KnockOut ${ }^{\mathrm{TM}}$ Serum Replacement (KSR, Gibco, Grand Island, NY, USA) and capacitated for $30 \mathrm{~min}$. Capacitated spermatozoa were added $\left(1-2 \times 10^{6} / \mathrm{mL}\right)$ to eggs in HTF medium and incubated for $6 \mathrm{~h}$ with or without $\omega$-Conotoxin CnVIIA, a specific Blocker of $\mathrm{N}$-Type $\left[\mathrm{Ca}^{2+}\right] \mathrm{i}$ Channels (Alomone Labs, Jerusalem, Israel). Fertilization rate was calculated as percentage of eggs transforming into two pronuclei $(2 \mathrm{PN})$ at $8 \mathrm{~h}$ post-insemination. Blastocyst formation rate was calculated as percentage of $2 \mathrm{PN}$ transforming into blastocysts. The quality of blastocysts was analyzed on the basis of morphological characteristics and with immunofluorescence analysis.

\section{Statistical analysis}

All the results were originated from at least three independent experiments. All statistical analyses were performed using Student's $t$ tests with GraphPad Prism 7 (GraphPad Software, La Jolla, CA, USA).p-values lower than 0.05 or 0.001 were considered statistically significant.

\section{RESULTS}

\section{Effect of extracellular calcium ion on $\left[\mathrm{Ca}^{2+}\right]$ i oscillation during mouse fertilization}

To investigate the effect of extracellular $\mathrm{Ca}^{2+}$ ion on $\left[\mathrm{Ca}^{2+}\right]$ i oscillation, we tested $\mathrm{Ca}^{2+}$ free 
medium with porcine sperm factor $(\mathrm{pSF}) \cdot \mathrm{pSF}$ is a strong $\left[\mathrm{Ca}^{2+}\right]$ i oscillation inducer in mouse eggs. However, in $\mathrm{Ca}^{2+}$ free medium, $\left[\mathrm{Ca}^{2+}\right]$ i oscillations were abolished completely (Fig. 1A). Another $\left[\mathrm{Ca}^{2+}\right]$ i oscillation inducer, Adenophostin A (Ad A) is a potent IP3R agonist which is much more potent than $\mathrm{IP}_{3}$. Microinjection of $\mathrm{Ad} A$, also showed strong $\left[\mathrm{Ca}^{2+}\right]$ i oscillation, but not in Latrunculin A (Lat A) contained medium (Fig. 1 B). Lat A, known as actin filament disruptor, also has the ability to inhibit $\mathrm{Ca}^{2+}$ influx. To analyze $\mathrm{Ca}^{2+}$ influx activity of Lat $\mathrm{A}$, we induced storeoperated $\mathrm{Ca}^{2+}$ entry (SOCE) using thapsigargin (TG) and $\mathrm{Ca}^{2+}$. After $\mathrm{Ca}^{2+}$ store depletion by $\mathrm{TG}$, addition of $5 \mathrm{mM} \mathrm{CaCl}_{2}$ into medium induces $\mathrm{Ca}^{2+}$ influx from extracellular environment. Lat $\mathrm{A}$ treatment inhibited $\mathrm{Ca}^{2+}$ influx with $5 \mathrm{mM} \mathrm{CaCl}_{2}$ (Fig. 1C). The above results indicate that the

A Ca2+containing $(24 / 26)$
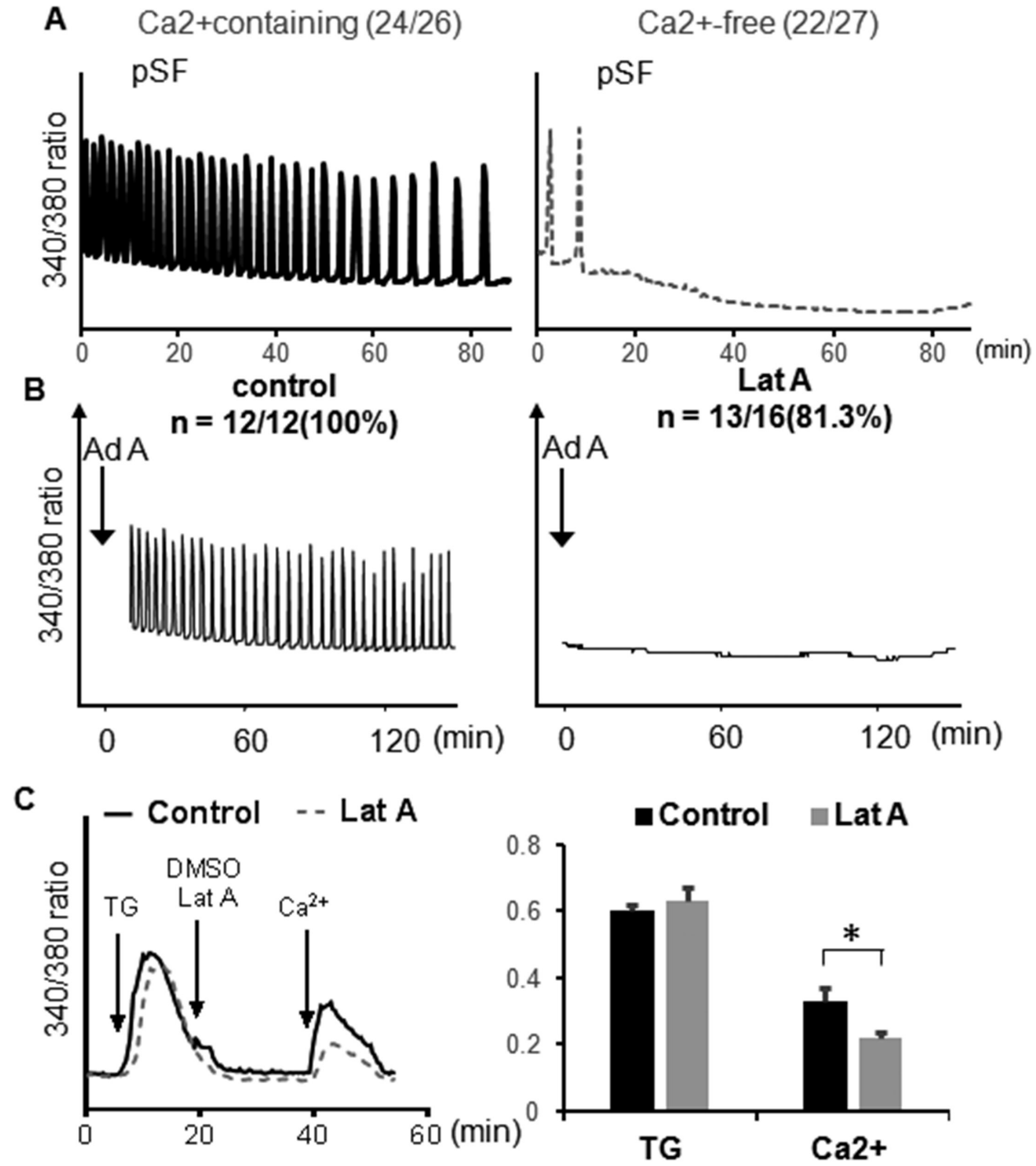

Fig. 1. $\left[\mathrm{Ca}^{2+}\right]$ i oscillation in $\left[\mathrm{Ca}^{2+}\right]$ i free medium or Latrunculin $\mathrm{A}$. (A) Effect of $\left[\mathrm{Ca}^{2+}\right]$ in medium on $\left[\mathrm{Ca}^{2+}\right]$ i oscillation by porcine sperm factor $(0.05 \mu \mathrm{g} / \mathrm{mL})$ in mouse Mll eggs. [Ca $\left.{ }^{2+}\right]$ i oscillation was abolished in the $\left[\mathrm{Ca}^{2+}\right]$ i free medium. Parentheses represent the experimental number of eggs. (B) The effect of latrunculin $\mathrm{A}$ (at a concentration of $2.5 \mu \mathrm{M})$ on $\mathrm{Ad} \mathrm{A}(10 \mu \mathrm{M})$ induced $\left[\mathrm{Ca}^{2+}\right]$ i oscillation in Mll eggs. The Mll eggs were micro-injected with $\mathrm{Ad} A$ and then divided into two groups in the control or Lat A-containing medium. The majority of eggs did not show $\left[\mathrm{Ca}^{2+}\right]$ i oscillation with latrunculin $\mathrm{A}$. (C) $\left[\mathrm{Ca}^{2+}\right] \mathrm{i}$ alterations were traced by the addition of thapsigargin (arrow, TG, $10 \mu \mathrm{M}$ ), and $\left[\mathrm{Ca}^{2+}\right]$ influx was induced by the addition of $5 \mathrm{mM} \mathrm{CaCl} 2$. The table represents quantitative analyses of the thapsigargin response and $\left[\mathrm{Ca}^{2+}\right]$ influx in controls $(n=18)$ and Lat $A(n=15)$ eggs. ${ }^{*} p<0.05$. 
$\left[\mathrm{Ca}^{2+}\right]$ i oscillation that appears during fertilization is introduced from the extracellular environment, which is through the $\mathrm{Ca}^{2+}$ channel.

\section{Immunolocalization of $\mathrm{N}$-type and $\mathrm{P} / \mathrm{Q}$ type of VDCCs}

The distribution of N-type and P/Q type VDCCs were examined in mouse eggs using antibody, localized on the plasma membrane of anti-CACNA1B $\left(\mathrm{Ca}_{\mathrm{v}} 2.2\right)$ antibody for $\mathrm{N}$-type VDCC or anti-CACNA1B ( $\left.\mathrm{Ca}_{\sqrt{ }} 2.1\right)$ antibody for P/Q type VDCCs. Mature metaphase II eggs contained both VDCCs in the cortex, and little staining was observed in the interior of the eggs. Both VDCCs were not observed near spindle and cortical granule free domain (Liu, 2011). Also, VDCCs on the cortex were organized clusters, $1-2 \mu \mathrm{m}$ in diameter (Fig. 2, yellow arrow). Some clusters of P/Q type VDCCs in interior of the eggs were more than $3 \mu \mathrm{m}$ in diameter (Fig. 2, yellow arrow head).

\section{Effect of $\mathrm{N}$-type voltage dependent $\left[\mathrm{Ca}^{2+}\right]$ i channels (VDCCs) blocker, $\omega$-Conotoxin CnVI- IA on $\left[\mathrm{Ca}^{2+}\right]$ i oscillation by $\mathrm{SrCl}_{2}$ egg activation}

To eliminate the potential effects of VDCC inhibitors on sperm fertility including, sperm motility, acrosome reaction, we used $\mathrm{SrCl}_{2}$ for egg activation during $\left[\mathrm{Ca}^{2+}\right]$ i monitoring. In 10 $\mathrm{mM} \mathrm{SrCl} 2$ in $\left[\mathrm{Ca}^{2+}\right]$ i free CZB medium, eggs showed average 3-4 spikes per 90 min, however, in $\omega$-Conotoxin CnVIIA containing medium, 21 out of 31 eggs showed 6-7 spikes/90 min 10 out of 31 eggs showed less than 3 spikes $/ 90$ min (Fig. 3A). In analytic data of $\left[\mathrm{Ca}^{2+}\right]$ i oscillation pattern, there are no statistical difference in intracellular $\mathrm{Ca}^{2+}$ concentration, basal level, the amplitude of spike (Max-min), and duration of spikes, but the number of spikes per 90 min represented higher in $\omega$-Conotoxin CnVIIA compare to control.

\section{Effect of $\mathrm{N}$-type voltage dependent $\left[\mathrm{Ca}^{2+}\right]$ i channels (VDCCs) blocker, $\omega$-Conotoxin $\mathrm{CnVI-}$ IA on fertilization and embryonic development}

Mature eggs were preincubated in $1 \mu \mathrm{M} \omega$-Conotoxin CnVIIA for $1 \mathrm{hr}$ in HTF medium and fertilized with capacitated sperm in same medium. Two pronucleus zygotes were collected at $8 \mathrm{~h}$ post fertilization. There is no difference in fertilization rate (2PN/MII eggs, Fig. 4A and B), but blastocyst formation were inhibited in $\omega$-Conotoxin CnVIIA compare to control (BL/2Cell).

\section{DISCUSSION}

$\left[\mathrm{Ca}^{2+}\right]$ i serves as a second messenger in many signal transductions. In hormone- sensitive cells, neurons, muscle, and many other cells that respond to extracellular signals, $\mathrm{Ca}^{2+}$ serves as a second messenger to triggers intracellular response (Conrard \& Tyteca, 2019). Free $\mathrm{Ca}^{2+}$ cytoplasmic concentration is kept very low at resting state 10-100 nM, in comparison to the ER / sarcoplasmic reticulum $(60-500 \mathrm{nM})$ and the extracellular medium or serum $(1.8 \mathrm{mM})$ (Conrard \& Tyteca, 2019). The voltage dependent $\mathrm{Ca}^{2+}$ channels (VDCCs) activates on membrane depolarization and mediates $\mathrm{Ca}^{2+}$ influx in response to action potentials and subthreshold depolarization signals (Catterall, 2011). Also, VDCCs plays an essential role in mammalian oocyte maturation (Lee et al., 2004). There are at least six pharmacologically distinct calcium channels types, including L-, N-, P/Q-, T, and R-type calcium channels (Catterall, 2000). The mammalian genome encodes as many as ten different genes that lead to different types of $\mathrm{Cav}$ subunits, the principal pore forming subunit that forms the core of the calcium permeable ion channel, and have been grouped into three major class such as Cav1, Cav2, and Cav3. Four different L-type VDCCs were encodes in 


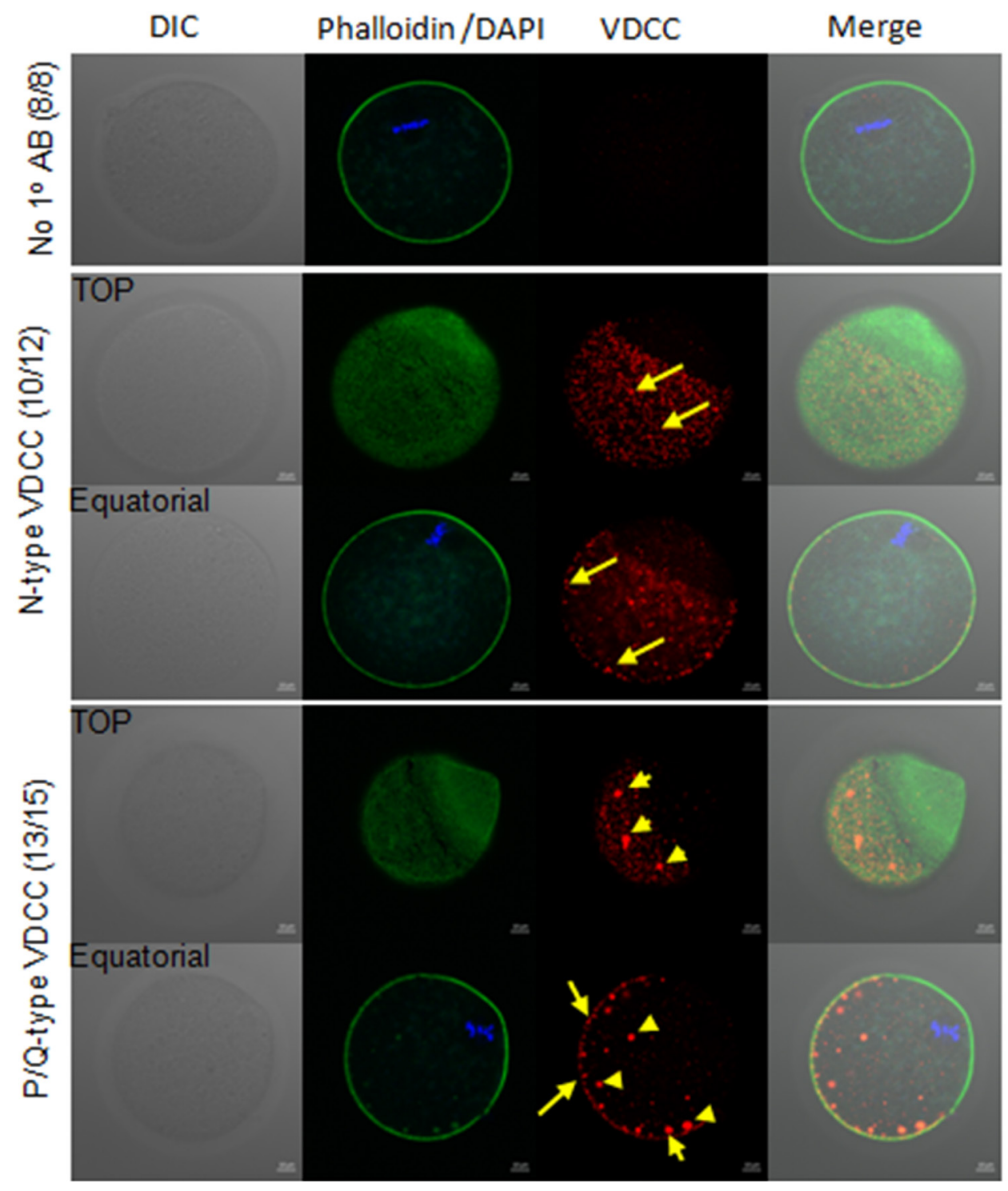

Fig. 2. Distribution of $\mathrm{N}$-type or $\mathrm{P} / \mathrm{Q}$-type VDCC on mature mouse eggs. Voltage-dependent $\mathrm{Ca}^{2+}$ channel (VDCC) localization and distribution in mouse ovulated eggs (red). P/Q-and N-type VDCCs were distributed on the plasma membrane with clusters $(3 \mu \mathrm{m}$ in diameter, yellow arrow), and some patch forms (more than $3 \mu \mathrm{m}$ in diameter, yellow arrow head) of P/Q-type VDCCs were localized in the cytoplasm. Neither VDCCs were distributed in the cortical granule-free region. Each egg was observed and sectioned using a confocal laser scanning microscope from top to bottom of the egg at 8-10 $\mu \mathrm{m}$ thickness intervals. The images represent the top and equatorial regions of the same eggs. The number of parentheses in the figure indicates the experimental number of eggs. Scale bar $=10 \mu \mathrm{m}$. Negative controls were stained with DAPI (blue) without the primary antibody.

Cav1. Cav1-3 encodes P/Q, N, and R-type VDCCs respectively. The last Cav3 family represents T-type VDCCs (Bourinet \& Zamponi, 2017). Various peptide toxins extracted from marine snails (conotoxins) and spiders (agatoxins, grammotoxin and DW13.3 Filistata hibernalis) are known to potently inhibit the activity of certain voltage-dependent calcium channels (Bourinet \& Zamponi, 2017). The $\omega$-conotoxin used in this study is a small peptide ranging in size from 13 to 30 amino acids, and are selective for N-type VDCCs. $\omega$-conotoxin is by blocking the channel pore, which is accomplished by tight binding of the toxin to channel pore (Ramirez et al., 2017).

In this study, we investigated the effect of extracellular $\mathrm{Ca}^{2+}$ on $\left[\mathrm{Ca}^{2+}\right]$ i oscillation during 
A

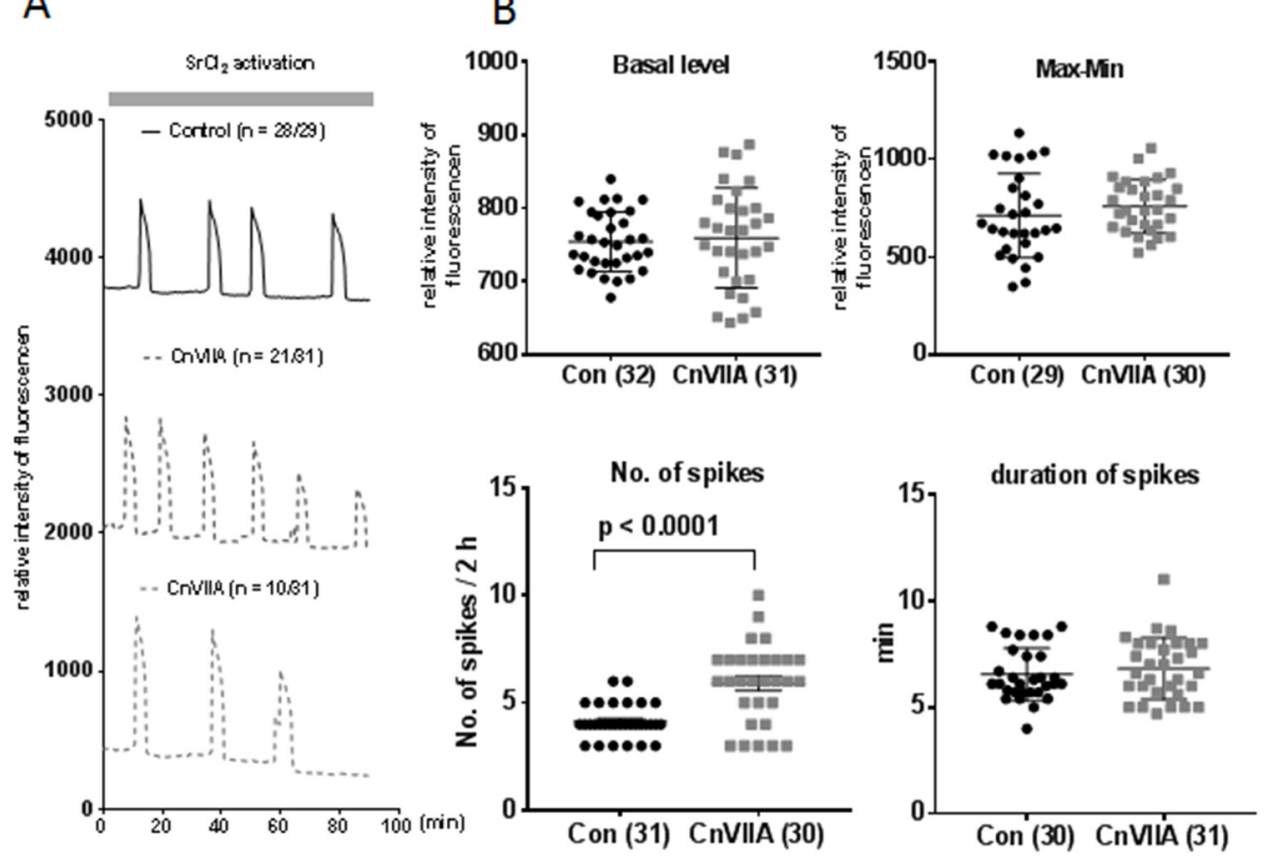

Fig. 3. Effect of $\mathrm{N}$-type voltage dependent calcium channel (VDCC) blocker, $\omega$-Conotoxin $\mathrm{CnVIIA}$, on $\left[\mathrm{Ca}^{2+}\right] \mathrm{i}$ oscillation by $\mathrm{SrCl}_{2}$ egg activation. (A) $10 \mathrm{mM} \mathrm{SrCl}_{2}$ in $\left[\mathrm{Ca}^{2+}\right]$ i free TL-HEPES medium. Parenthesis in each group represents egg number /total egg number. (B) Relative fluorescence intensity was calculated using the basal level of $\left[\mathrm{Ca}^{2+}\right]$ and the amplitude of $\left[\mathrm{Ca}^{2+}\right]$ i spikes (max-min). The number of spikes per $2 \mathrm{~h}$ and duration of each spike were determined from (A). Each dot represents the number of eggs.

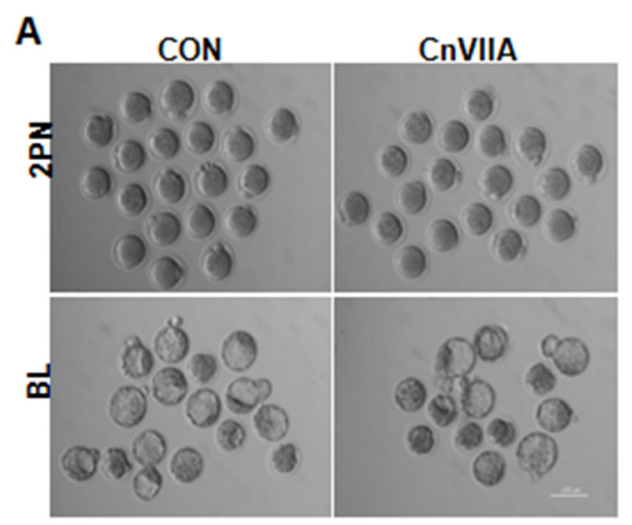

B

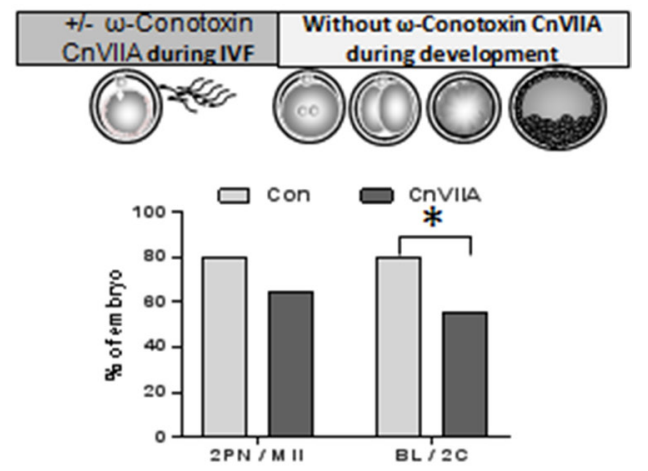

Fig. 4. Effect of N-type voltage dependent calcium channel (VDCC) blocker, w-Conotoxin CnVIIA, on fertilization and embryonic development. Mature eggs were incubated for $1 \mathrm{hr}$ with $\omega$-Conotoxin CnVIIA and fertilized with BDF1 sperm in the same medium for $8 \mathrm{~h}$. (A) Two pronuclear zygotes were collected and cultured in KSOM for five days. (B) Fertilization rates were calculated at 2 cells per MII mature eggs, and the blastocyst rate were calculated from 2-cells. ${ }^{*} p<0.05$.

fertilization. Porcine sperm factor is a strong inducer of $\left[\mathrm{Ca}^{2+}\right] \mathrm{i}$ oscillation in mouse eggs (Kurokawa et al., 2007). It has higher frequency of $\left[\mathrm{Ca}^{2+}\right]$ i oscillation mouse sperm in mouse eggs (Kurokawa et al., 2005). However, it could not induce $\left[\mathrm{Ca}^{2+}\right]$ i oscillation in $\mathrm{Ca}^{2+}$ free medium except the initial $\mathrm{Ca}^{2+}$ spikes (Fig. 1A). Also, a non-hydrolyzable analogue of $\mathrm{IP}_{3}$, adenophostin $\mathrm{A}(\mathrm{Ad} \mathrm{A}$ ) is a strong inducer $\left[\mathrm{Ca}^{2+}\right]$ i oscillation. It could produce a $\mathrm{Ca}^{2+}$ release from intracellular $\mathrm{Ca}^{2+}$ store, such as ER (Jellerette et al., 2004). In this study, Ad A could not induce $\left[\mathrm{Ca}^{2+}\right]$ i oscillation in $\left[\mathrm{Ca}^{2+}\right]$ i free 
condition (Fig. 1 B). These results support that $\left[\mathrm{Ca}^{2+}\right]$ i oscillation during fertilization necessities the extracellular $\mathrm{Ca}^{2+}$ ion. Latrunculin A (Lat A) has been known as an actin polymerization inhibitor, which disrupted intracellular $\left[\mathrm{Ca}^{2+}\right] \mathrm{i}$ channels on the $\mathrm{ER}$, inositol 1,4,5 triphosphate receptors (Wakai et al., 2012). In this study, Lat A inhibited $\left[\mathrm{Ca}^{2+}\right]$ i influx by store operated $\left[\mathrm{Ca}^{2+}\right]$ influx (Fig. 1C). These results represented that the $\left[\mathrm{Ca}^{2+}\right]$ i oscillation during fertilization needed the $\left[\mathrm{Ca}^{2+}\right]$ influx through $\left[\mathrm{Ca}^{2+}\right]$ i channel on the plasma membrane.

External $\left[\mathrm{Ca}^{2+}\right]$ i can enter cells through channels and/or transporters. The T-type voltage-gated $\left[\mathrm{Ca}^{2+}\right]$ i channel (CaV 3.2) (Kang et al., 2007) was one of the first characterized channels in mouse eggs, although its function is still unclear because female mutant mice lacking $\mathrm{CaV} 3.2$ are fertile (Chen et al., 2003). To investigate whether VDCCs other than the T-type VDCCs are involved in mouse egg fertilization, immunofluorescence staining was performed using P/Q and N-type VDCCs antibodies. In addition, in the P/Q type, fluorescent staining of patches with a diameter of $3 \mu \mathrm{m}$ or more was observed in the eggs cytoplasm (Fig. 2). Next, inhibitor of N-type VDCCs, $\omega$-Conotoxin CnVIIA interrupted $\left[\mathrm{Ca}^{2+}\right]$ i oscillation during fertilization. The pattern of $\left[\mathrm{Ca}^{2+}\right] \mathrm{i}$ oscillation during fertilization was known as key regulator of further embryonic development (Ozil et al., 2006). Egg activation comprised a temporal serious of $\left[\mathrm{Ca}^{2+}\right]$ i dependent events, that include cortical granule exocytosis, cell cycle resumption with change of MPF/MAP kinase activities, and recruitment of maternal mRNAs (Ducibella et al., 2002; Ajduk et al., 2008). In this study, we used $10 \mathrm{mM} \mathrm{SrCl}_{2}$ to induce $\mathrm{Ca}^{2+}$ oscillation and to eliminate the effect of VDCCs inhibitor on sperm physiology (Rahban \& Nef, 2020). The $\left[\mathrm{Ca}^{2+}\right]$ i oscillation pattern of $\omega$-Conotoxin CnVIIA is different compared to the control. Most of the eggs showed a higher frequency than control or less frequency of $\left[\mathrm{Ca}^{2+}\right]$ i oscillation (Fig. 3B). And those eggs showed a low amplitude of $\left[\mathrm{Ca}^{2+}\right]$ i spike at end of $\left[\mathrm{Ca}^{2+}\right]$ i oscillation. These results indicate a reduction in $\left[\mathrm{Ca}^{2+}\right]$ i retention by $\omega$-Conotoxin CnVIIA. Last, we investigated the effect of inhibition $\mathrm{N}$-type VDCCs using $\omega$-Conotoxin CnVIIA on embryonic development. There is no statistic differences in fertilization, but blastocyst formation was inhibited by $\omega$-Conotoxin CnVIIA treatment during fertilization. In the Fig. 3, we did not observe long term $\left[\mathrm{Ca}^{2+}\right]$ i monitoring, but most of the eggs showed a decrease of amplitude of $\left[\mathrm{Ca}^{2+}\right]$ i spike. Compared to the control, it can be seen that $\left[\mathrm{Ca}^{2+}\right]$ i oscillations were induced to stop prematurely, and the signal transduction required for sufficient egg activation eventually failed (Ducibella et al., 2002). Also, functional inhibition of VDCCs induced abnormal $\left[\mathrm{Ca}^{2+}\right]$ i oscillation during fertilization or egg activation process might be the reason of poor embryogenesis (Fig. 4).

In the present study, we confirmed that VDCCs were present in ovulated mouse eggs. $\mathrm{Ca}^{2+}$ influx is essential for $\mathrm{Ca}^{2+}$ oscillations during mammalian fertilization. This $\mathrm{Ca}^{2+}$ influx may be controlled through the N- or P/Q-type voltage dependent $\mathrm{Ca}^{2+}$ channel. Functional inhibition of the P/Q-type VDCC requires further investigation. Abnormal VDCC expression in eggs should be tested in fertilization failure or low fertilization eggs in infertile/subfertile women.

\section{REFERENCES}

Ajduk A, Małagocki A, Maleszewski M (2008) Cytoplasmic maturation of mammalian oocytes: Development of a mechanism responsible for sperm-induced $\mathrm{Ca}^{2+}$ oscillations. Reprod Biol 8:3-22.

Berridge MJ (2014) Calcium regulation of neural rhythms, memory and Alzheimer's disease. J Physiol 592:281-293.

Bourinet E, Zamponi GW (2017) Block of voltage-gated calcium channels by peptide toxins. Neuropharmacology 127:109-115. 
Catterall WA (2000) Structure and regulation of voltage-gated $\mathrm{Ca}^{2+}$ channels. Annu Rev Cell Dev Biol 16:521-555.

Catterall WA (2011) Voltage-gated calcium channels. Cold Spring Harb Perspect Biol 3:a003947.

Chen CC, Lamping KG, Nuno DW, Barresi R, Prouty SJ, Lavoie JL, Cribbs LL, England SK, Sigmund CD, Weiss RM, Williamson RA, Hill JA, Campbell KP (2003) Abnormal coronary function in mice deficient in alpha1H T-type $\mathrm{Ca}^{2+}$ channels. Science 302:1416-1418.

Conrard L, Tyteca D (2019) Regulation of membrane calcium transport proteins by the surrounding lipid environment. Biomolecules 9:51.

Ducibella T, Huneau D, Angelichio E, Xu Z, Schultz RM, Kopf GS, Fissore R, Madoux S, Ozil JP (2002) Egg-to-embryo transition is driven by differential responses to $\mathrm{Ca}^{2+}$ oscillation number. Dev Biol 250:280-91.

Hotsuliak IM, Berdyieva TK, Libert SV (2002) Effects of T-type calcium channel blockers on spontaneous meiotic maturation of mouse ovarian oocytes in vitro. Fiziol Zh 48:98-101.

Jellerette T, Kurokawa M, Lee B, Malcuit C, Yoon SY, Smyth J, Vermassen E, De Smedt H, Parys JB, Fissore RA (2004) Cell cycle-coupled $\left[\mathrm{Ca}^{2+}\right]_{\mathrm{i}}$ oscillations in mouse zygotes and function of the inositol 1,4,5-trisphosphate receptor-1. Dev Biol 274:94-109.

Kang D, Hur CG, Park JY, Han J, Hong SG (2007) Acetylcholine increases $\mathrm{Ca}^{2+}$ influx by activation of CaMKII in mouse oocytes. Biochem Biophys Res Commun 360:476-482.

Kim BY, Yoon SY, Cha SK, Kwak KH, Fissore RA, Parys JB, Yoon TK, Lee DR (2011) Alterations in calcium oscillatory activity in vitrified mouse eggs impact on egg quality and subsequent embryonic development. Pflugers Archiv 461:515-526.

Kurokawa M, Sato KI, Wu H, He C, Malcuit C, Black SJ, Fukami K, Fissore RA (2005) Functional, biochemical, and chromatographic characterization of the complete $\left[\mathrm{Ca}^{2+}\right]_{\mathrm{i}}$ oscillation-inducing activity of porcine sperm. Dev Biol 285:376-392.

Kurokawa M, Yoon SY, Alfandari D, Fukami K, Sato KI, Fissore RA (2007) Proteolytic processing of phospholipase Czeta and $\left[\mathrm{Ca}^{2+}\right]_{i}$ oscillations during mammalian fertilization. Dev Biol 312:407-418.

Lee HC, Yoon SY, Lykke-Hartmann K, Fissore RA, Carvacho I (2016) TRPV3 channels mediate $\mathrm{Ca}^{2+}$ influx induced by 2-APB in mouse eggs. Cell Calcium 59:21-31.

Lee JH, Yoon SY, Bae IH (2004) Studies on $\mathrm{Ca}^{2+}$-channel distribution in maturation arrested mouse oocyte. Mol Reprod Dev 69:174-185.

Liu M (2011) The biology and dynamics of mammalian cortical granules. Reprod Biol Endocrinol 9:149.

Malcuit C, Kurokawa M, Fissore RA (2006) Calcium oscillations and mammalian egg activation. J Cell Physiol 206:565-573.

Miyazaki S, Shirakawa H, Nakada K, Honda Y (1993) Essential role of the inositol 1,4,5-trisphosphate receptor/ $\mathrm{Ca}^{2+}$ release channel in $\mathrm{Ca}^{2+}$ waves and $\mathrm{Ca}^{2+}$ oscillations at fertilization of mammalian eggs. Dev Biol 158:62-78.

Ozil JP, Banrezes B, Tóth S, Pan H, Schultz RM (2006) $\mathrm{Ca}^{2+}$ oscillatory pattern in fertilized mouse eggs affects gene expression and development to term. Dev Biol 300:534-544.

Parrish JJ, Susko-Parrish J, Winer MA, First NL (1988) Capacitation of bovine sperm by heparin. Biol Reprod 38:1171-1180.

Petr J, Rozinek J, Jilek F (1997) Cyclopiazonic acid induces accelerated progress of meiosis in pig oocytes. Zygote 5:193-205.

Rahban R, Nef S (2020) CatSper: The complex main gate of calcium entry in mammalian spermatozoa. Mol Cell Endocrinol 518:110951.

Ramirez D, Gonzalez W, Fissore RA, Carvacho I (2017) Conotoxins as tools to understand the 
physiological function of voltage-gated calcium $\left(\mathrm{Ca}_{\mathrm{V}}\right)$ channels. Mar Drugs 15:313.

Takahashi T, Kikuchi T, Kidokoro Y, Shirakawa H (2013) $\mathrm{Ca}^{2+}$ influx-dependent refilling of intracellular $\mathrm{Ca}^{2+}$ stores determines the frequency of $\mathrm{Ca}^{2+}$ oscillations in fertilized mouse eggs. Biochem Biophysi Res Commun 430:60-65.

Wakai T, Vanderheyden V, Yoon SY, Cheon B, Zhang N, Parys JB, Fissore RA (2012) Regulation of inositol 1,4,5-trisphosphate receptor function during mouse oocyte maturation. J Cell Physiol 227:705-717.

Yoon SY, Kang DW (2011) Production of intracellular calcium oscillation by phospholipase C zeta activation in mammalian eggs. Dev Reprod 15:197-204. 